\title{
Fear of Childbirth: A Mini Review
}

\author{
Supatra Pinkaew and Watcharaporn Paorohit* \\ Royal Thai Air Force Nursing College, Thailand. \\ Submission: January 25, 2020; Published: January 29, 2020 \\ *Corresponding author: Watcharaporn Paorohit, Royal Thai Air Force Nursing College, Thailand
}

\begin{abstract}
Fear of childbirth is one of the common problems found among pregnant women. It affects on a negative impact on a birth process. The objectives of this review are to explore factor related to fear of childbirth, consequences of fear of childbirth and assessment of fear of childbirth. A review was conducted in the electronic databases Pub Med, Science Direct, and CINAHL. Keywords used in the search were 'fear' in conjunction with 'childbirth'. Combination of components of the Problem, Intervention, Comparison and Outcome strategy were used. The timeframe was limited to the years 1947-2019, as it was the timeframe where fear of childbirth made an appearance in the literature. The search was limited to English language articles. The results revealed factor related to fear of childbirth as prospective fear which composed of social aspect and personal aspect and retrospective fear. Consequences of fear of childbirth were decisions for future pregnancy and prolong labor. The measurements scales of fear of childbirth were Childbirth Attitudes Questionnaire and Wijma Delivery Expectancy/Experience Questionnaire (W-DEQ).
\end{abstract}

Keywords: Fear; Childbirth; Pregnant women; Delivery Expectancy

\section{Introduction}

Fear of childbirth is a common problem found among pregnant women. Rate of fear of childbirth varied depended on many factors. Some qualitative studies revealed women did not perceived childbirth as a natural event but as a fearful event [1]. Many women had negative experiences in the delivery room, a place creating fear of childbirth. Review of related literature and research on fear related-childbirth had shown that Scandinavian countries had considerable attention to fear of childbirth. A study on Norwegian sample found $7.5 \%$ of all pregnant women suffered from childbirth fear [2]. Similar figure were found in Finland study, with $7.0 \%$ in nulliparous and $7.7 \%$ in parous women experiencing fear of childbirth [3]. The high rates of childbirth fear had been reported in Sweden, with $12.4 \%$ in mid-pregnancy, $13.5 \%$ in late pregnancy and $15.1 \%$ one year after childbirth [4].

The rate of women confronted with childbirth related fear had shown its effect on negative consequents as shown in the previous studied revealed fear of childbirth during pregnancy had negative impacts on a birth process. A few studies fond fear of childbirth associated with prolonged labor. A comparative study in Norway revealed duration of labor were longer among women with fear of childbirth than women without fear [2] and associated with dystocia or protracted labor [5]. Long duration of labor or dystocia could contribute to instrument delivery or negative outcome of delivery. Several studied disclosed the risk of emergency cesarean section increased when pregnant women suffered from fear of childbirth [6]. A consequence, cesarean section could lead to emergency peripartum hysterectomy and maternal mortality. An essential potential was the danger of giving birth related to fear. Pregnant women could overcome the problem of fear of childbirth together with midwives and also needed support during pregnancy from the family. Thus, it is important to explore fear of childbirth, its consequences and knowing how fear of childbirth they were to avoid unnecessary suffering during pregnancy and to prevent future fear of childbirth.

\section{Objective of the Study}

The objectives of this review are to explore factor related to fear of childbirth, consequences of fear of childbirth and assessment of fear of childbirth.

\section{Method}

A review was conducted in the electronic databases Pub Med, Science Direct, and CINAHL. Keywords used in the search were 'fear' in conjunction with 'childbirth' Combination of components of Patient Problem, Intervention, Comparison and Outcome (PICO). These four components are the essential elements of the research question in evidence based practice and of the construction of the question for the bibliographic search of evidence [7]. Related articles were searched. To accurately answer 
the questions that guided this review, the abstracts were read and classified during a selection process. If, after reading the abstract, there was reasonable doubt about the inclusion or exclusion of the paper, the whole article was read. Thereafter, a reverse search was carried out.

\section{Study selection and characteristics}

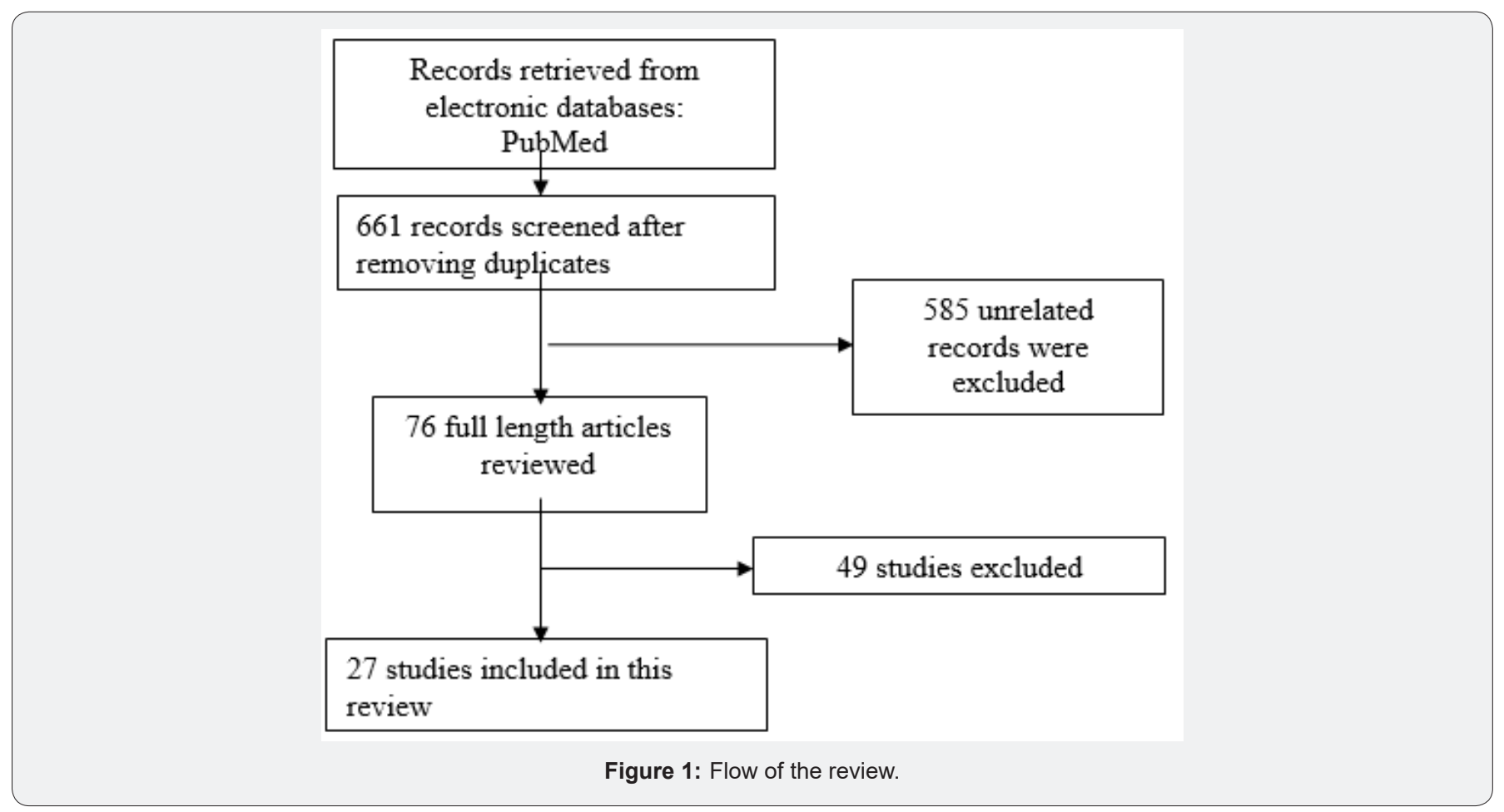

The total searches were identified 661 citations, unrelated articles were removed, citations were reduced to 27 studies which were from Thailand, Denmark, Australia, Sweden, Finland, Iran, Norway, Greece, UK, and Turkey. Sample size of pregnant women ranged from 30 to 2,206 (Figure 1).

\section{Fear of childbirth}

In the context of childbirth, Lockiophobia is the similar word of fear of childbirth. People with this phobia tend to fear how a pregnancy may change their life and body, if the child will be born normal and healthy or if they will die giving birth to the child. The origin of the word comes from lochio, which is Greek (meaning childbirth) and phobia is Greek (meaning fear). Lockiophobia is considered to be a specific phobia, which is discussed on the home page. Lockiophobia is also called Maieusiophobia or Parturiphobia or Tocophobia or Tokophobia and related to Teratophobia (fear of monsters, bearing a deformed child or deformed people [8]. Qualitative study revealed women did not perceived childbirth as a natural event but as a life threaten event. The issues of fear included: the baby's well being, pain and difficulty of childbirth [1]. Women's sense of fear has been linked to their satisfaction with the birth experiences, which can ultimately affect women's future decisions pregnancy and childbirth [1].

\section{Factors related to fear of childbirth}

The study unveiled two attributes were potential factors related to fear of childbirth among childbearing women. Prospective and retrospective fear.

\section{Prospective fear}

Prospective fear was the expectation of unwanted and fearful event they may have during childbirth. The study found prospective fear components were both social aspect and personal aspects.

\section{Social Aspect}

Social aspect was explored and discovered among pregnant women shared their similar childbirth experiences of fear through sentiment of "unknown". A horror birth story related to fear of childbirth could lead to the negative birth stories of significant others and become dominant concerns toward their own birth. Complicated birth of their own mother and siblings provided a strong reference of childbirth fear [9-11]. Fear of not being good enough mother also uncovered along with loss of physical and emotional control [10-12].

\section{Personal aspect}

Personal aspects were disclosed with some issues related to fear of pain and difficulty of childbirth $[1,11]$. Fear of delivery 
procedure related to childbirth process; episiotomy, vaginal examination, and the used of invasive procedures; vacuum or forceps $[1,9,10]$. Fears of well being of the baby were expressed by pregnant women $[1,10]$. Despite being a natural event, childbirth was perceived as possible risk. Some pregnant women were afraid that they would die because of severe pain [11].

\section{Retrospective fear}

Retrospective fear related to women's previous experiences of negative or harrowing, inevitably event which could induce fear for future childbirth. A previous negative experience of pregnancy and childbirth contributes mostly to the fear of future childbirths in parous women, and was one of the most common reasons for requesting a cesarean section among parous women $[1,10,12]$.

\section{The consequences of fear of childbirth}

Fear of childbirth was not only a common problem among pregnant women but also a perception of a disruptive for minority of them. A qualitative study revealed Thai women did not perceive childbirth as a nature of life but as a life threatening situation [1,2]. Women's sense of fear had been linked to their satisfaction with the birth experiences which could ultimately affect on women's future decisions for future pregnancy and childbirth [1]. Due to the relationship between women's sense of fear of childbirth and the potential of unsatisfied perinatal outcomes, it had shown fear of childbirth had a negative impact on a delivery process. A few studies indicated fear of childbirth associated with prolonged labor. The recent study in Norway disclosed duration of labor was longer than usual in women with fear of childbirth compared to women without fear of childbirth [2]. Some studied described an increased risk of emergency cesarean section when pregnant women suffered from fear of childbirth $[6,13]$.

\section{Assessment of fear of childbirth}

The first studies on fear of childbirth was developed and done by interviewing 139 low-risk women during their third trimester of pregnancy, and combining the results with those of a new questionnaire 19 items on childbirth, assessment of the prevalence of moderate fear of childbirth $17 \%$ and severe fear of childbirth $6 \%$. The results of the study led to the development of a questionnaire which has been used and revised by other countries [14].

\section{Fear of Childbirth Scale Childbirth Attitudes Questionnaire (CAQ)}

Childbirth Attitudes Questionnaire referred to the measurement of Fear of Childbirth by rating scale. It was adapted to measure fear of childbirth. The questionaires composed of 16item with a Likert response scale of 1-4, higher scores represent higher fear. Scores were computed by the mean of the 16 items [14]. A reported of internal consistency reliability estimate for the CAQ of 0.83 in the study of 280 nulliparous women attending childbirth education classes after 28 weeks of gestation [15].

\section{Wijma Delivery Expectancy/Experience Questionnaire (W-DEQ)}

The W-DEQ was a validated 33-item questionnaire, with scores ranging from 'not at all' (0) to 'extremely' [5], giving a minimum score of 0 and a maximum score of 165. A higher score indicates a more intense fear of childbirth. This means that the answers of those questions that are positively formulated, except item some numbers $(2,3,6,7,8,11,12,15,19,20,24,25,27$, 31 ) had to reversed for the calculation of the women's individual sum score [16]. It was translated and used in different country. In Turkish population, reliability and validity of the Turkish version of the Wijma Delivery Expectancy/ Experience Questionnaire was comprehensibility, internal consistency, validity were adequate and useful for assessment of fear of childbirth among Turkish pregnant women [16]. Wijma Delivery Expectancy/Experience Questionnaire W-DEQ was translated to Japanese version and employed among Japanese healthy pregnant women. W-DEQ was highly concurrent, convergent validity, reliability, and internal consistency [17].

\section{Conclusion}

The review identified 27 studies related to the fear of childbirth. The definition of the fear of childbirth was found in general meaning from the online dictionary and one qualitative study described meaning of the fear of childbirth as a fearful event. The issues of fear defined fear of the condition of baby's well being, pain and difficulty of childbirth [1]. The factors related to fear of childbirth were prospective fear which composed of social aspect and personal aspect and retrospective fear. Consequences of fear of childbirth were decisions for future pregnancy and prolong labor and request for cesarean section. The measurements scales of fear of childbirth were Childbirth Attitudes Questionnaire and Wijma Delivery Expectancy/Experience Questionnaire (W-DEQ). The review found less evidence base to support the effect of intervention to decrease the fear of childbirth.

\section{References}

1. Chuahorm U, Sripichyakarn K, Tungpunkom P, Klunklin A, Kennedy HP, et al. (2007) Fear and suffering during childbirth among Thai women. Thai Journal of Nursing Research 11(1): 49-61.

2. Adams S, Eberhard-Gran M, Eskild A (2012) Fear of childbirth and duration of labour: a study of 2,206 women with intended vaginal delivery. BJOG 119(10): 1238-1246.

3. Rouhe H, Salmela-Aro K, Halmesmaki E, Saistoa T (2008) Fear of childbirth According to parity, gestational age and obstetric history. BJOG 116(1): 67-73.

4. Engstrom A, Lindberg I (2011) Mothers' experiences of a stay in an ICU after a complicated childbirth. Nurs Crit Care 17(2): 64-70.

5. Laursen M, Hedegaard M, Johansen C, Danish National Birth Cohort (2007) Fear of childbirth: predictors and temporal changes among nulliparous women in the Danish National Birth Cohort. BJOG 115(3): 354-360.

6. Ryding EL, Lukasse M, Parys AV, Wangel AM, Karro H, et al. (2015) Fear of childbirth and risk of cesarean delivery: a cohort study in six European countries. Birth 42(1): 48-55. 
7. Santos CMC, Pimenta CAM, Nobre MRC (2007) The PICO strategy for the research question construction and evidence search. Rev Latinoam Enfermagem maio-junho 15(3): 508-511.

8. Fenwick J, Toohill J, Creedy DK, Smith J, Gamble J, et al. (2015) Sources responses and moderators of childbirth fear in Australian women: A qualitative investigation. Midwifery 31(1): 239-246.

9. Serc-ekus P, Okumus H (2009) Fears associated with childbirth among nulliparous women in Turkey. Midwifery 25(2): 155-162.

10. Fisher C, Hauck Y, Fenwick J (2006) How social context impacts on women's fears of childbirth: a western Australian example. Soc Sci Med 63(1): 64-75.

11. Melender H, Lauri S (1999) Fears associated with pregnancy and childbirth-experiences of women who have recently given birth. Midwifery 15(3): 177-182.

12. Shahoei R, Riji HM, Saeedi ZA (2011) 'Safe passage': pregnant Iranian Kurdish women's choice of childbirth method. J Adv Nurs 67(10): 2130-2138.

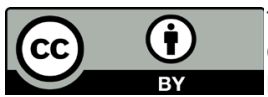

This work is licensed under Creative Commons Attribution 4.0 License

DOI:_10.19080/JGWH.2020.18.555984
13. Areskog B, Kjessler B, Uddenberg N (1982) Identification of women with significant fear of childbirth during late pregnancy. Gynecol Obstet Invest 13(2): 98-107.

14. Lowe N (2000) Self-efficacy for labor ad childbirth fears in nulliparous pregnant women. J Psychosom Obstet Gynaecol 21(4): 219-224.

15. Korucu O, Kokulu K, Firat MZ (2012) The reliability and validity of the Turkish version of the Wijma Delivery Expectancy/Experience Questionnaire (W-DEQ) with pregnant women. J Psychiatr Ment Health Nurs 19(3): 193-202

16. Takegata M, Haruna M, Matsuzaki M, Shiraishi M, Murayama R, et al. (2013) Translation and validation of the Japanese version of the Wijma Delivery Expectancy/Experience Questionnaire version A. Nurs Health Sci 15(3): 326-332.

\section{Your next submission with Juniper Publishers will reach you the below assets}

- Quality Editorial service

- Swift Peer Review

- Reprints availability

- E-prints Service

- Manuscript Podcast for convenient understanding

- Global attainment for your research

- Manuscript accessibility in different formats

( Pdf, E-pub, Full Tsext, Audio)

- Unceasing customer service

Track the below URL for one-step submission https://juniperpublishers.com/online-submission.php 